\title{
Juan Donoso
}

\section{Lorenzo Aedo}

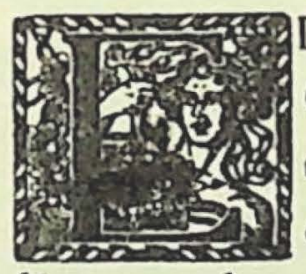

L INTELIGENTE y culto profesional que es Antonio Quiñones Hormazábal, amigo de escritores y artistas, charlador impenitente, solterón empedernido, aventurero disipado y generoso, cuya amistad me honra, me dijo en dias pasados: "Voy a narrarte un cuento que fue toda una realidad. Bien sabes que mis padres, de recién casados, se radicaron en el sur, para ser más preciso: en La Frontera - de esto hace unos cincuenta años-. ¡Era un bravo tiempo! Tiempo de lucha, esfuerzo, coraje y un no sé qué de aventura y epopeya. Los roces, el cuatrerismo, los asaltos y el capitán Trizzano hacían noticia diaria a lo largo del país.

Mis padres se habían radicado en el interior de Temuco, allí nacimos y crecimos siete hermanos hombres, llevando bien metido en las venas nombre y sello de gentes sureñas.

Mis padres eran oriundos del Norte Chico, pero terminaron por aquerenciarse a la nueva tierra y no hubo poder humano que les hiciera venirse a la capital, ni cuando lo exigieron nuestros estudios, ni después, cuando poseedores de nuestros títulos profesionales nos díspersamos desde Arica a Chillán.

¡Creo que mis viejos tuvieron sobrada razón para permanecer fieles a la tierra donde sus sueños y esperanzas fructificaron en for- 
ma más o menos pródiga, brindándoles una ancianidad de bien ganada felicidad y justo orgullo!

En nosotros, el amor podía más que la distancia. De vez en cuando recalábamos allá y cruzar el umbral de aquella puerta era entrar de lleno en nuestro pasado. ¡Todo se conservaba idéntico!, hasta el orden y adorno de nuestros cuartos de muchacho era exacto. Las innovaciones en general era mínimas y puedo decir con certeza que los únicos artefactos nuevos eran una electrola, un refrigerador y un automóvil.

En cierto modo, ¡sólo mis padres no iban siendo los mismos! ¡No así no más había pasado para ellos el curso de los años!, las luchas, los esfuerzos y las incertidumbres.

El corpachón de mi padre y esa entereza que distinguía cada uno de sus gestos, se habían ido haciendo cada vez más débil. Ella, mi madre, envejecía hermosamente, llena de bondad y dulzura, jverles juntos era algo envidiable!, a la vez que una elocuente amonestación a toda antipatía matrìmonial, especialmente para mí. Pero... esta solteronía me permitía gozar de una franquicia que mis hermanos no podían compartir; ellos, llegaban acompañados de sus mujeres, niños y criadas. ¡Todo un mundo de gentes que arrollaba la quietud patriarcal que irradiaba la venerable pareja!

En cambio, yo iba en invierno y gozaba más que todos ellos, pues no sólo me sentía remozar, sino que llegaba al extremo de creerme niño y regaloneaba con mis viejos, para quienes seguía siendo el pequeño Toño, que para felicidad de ellos había dejado los intolerables defectos de la infancia; escapadas a la lluvia, porfías, caprichos, preguntas indiscretas. En cambio, quien llegaba ahí era un hombre en busca de paz y quizá de una pura ternura...

Nuestras veladas se prolongaban más allá de la alta noche, al calor de la chimenea y de los recuerdos. Ellos me daban largas y minuciosas noticias sobre los conocidos; unos habían partido, otros muerto; muchos permanecían allí y se habían casado, tenían hijos y cada cual constituía una sabrosa historia. 
En otras oportunidades, recordaban su propia juventud, o bien, nuestra niñez, y me era dado comprobar con qué ternura, aquel par de viejos, mantenía nítidos infinidad de detalles; pequeños hechos, travesuras, frases, que hasta para nosotros mismos habían pasado inadvertidas y del todo olvidadas. En veces se recriminaban graciosamente, sobre tal o cual detalle, y jera de oirles!

- ¡Manuel Antonio era tu consentido, nadie podía decirle nada!

- iLo que hay de verdad es que estaba mayorcito! - replicaba mi padre- ¡Había que tratarle como a un hombre y allí estaba yo para eso!

¡Ni con eso! aquellos eran simples vilanos, que pasaban sin rozar siquiera aquella dicha perfecta.

Un día, recordamos la figura de un viejo servidor. ¡Y esta es la verdadera historia que voy a contarte!, todo este preámbulo no ha sido más que el recuerdo y cariño, sentimental, de un hombre que siente por la memoria de sus padres una verdadera devoción, el personaje de mi cuento tal cual fue tratado en aquella oportunidad, que tomaremos como última versión.

- ¿Y, tú Antonio, por qué no escribes estos cuentos o relatos? -anoté, una vez más, ya que mi amigo era un gran narrador de historias verídicas o fantásticas, en lo cual ponía verdadera gracia.

- ¿Te parece poco trabajo el contarlas? - fue su respuesta-. ¡Además de eso, quieres que las escribal A diario, no hago más que contar y atiborrar a mis amigos con narraciones de cuentos y capítulos de novelas, en la esperanza de que uno de tanto las escriba alguna vez. A mí me basta con idearlas o haberlas vivido... ¿Qué más se me puede pedir? ¿Qué más puedo desear o esperar? Pues bien, escucha: Al atardecer de un domingo, regresábamos a casa, luego de haber pasado el día en Temuco. Juan Miguel, el mayor de mis hermanos, conducía el carruaje. Era un muchacho de doce años, grande, fornido y muy despierto. No sé cómo pudo acontecer el percance que voy a referirte.

En el coche iba mi madre y mis cinco hermanos nacidos hasta entonces - yo entre los menores-, cuando en una curva del cami- 
no, nada más que por la caída del gajo de un árbol, se espantaron los caballos, pugnando de inmediato por trepar a las veras del camino medio encajonado, las bestias tiraban ya de un lado, ya del otro, con grave peligro de volcar el carruaje, que si bien es cierto que era un modelo especial para andar por aquellos andurriales, podía también volcarse.

A Juan Miguel se le soltaron las riendas cayendo entre las patas de los animales, contribuyendo a un mayor alboroto, pues arrancaron a la imperdible, coceando y haciendo saltar en astillas parte del pescante. Todos los muchachos nos agrupamos en el asiento trasero, entre llantos y gritos que no hacían más que azuzar a las despavoridas bestias. Mi madre hacía esfuerzos inaudizos por tranquilizarnos, dispuesta a pasar a la parte delantera y hacer cualquier acto heroico por salvarnos del peligro.

Providencialmente, caído del cielo, surgido de la tierra, pero, efectivamente salido de entre las zarzas, quilas y radales, apareció en medio del camino un hombre, que con voz de mucha autoridad y abriendo los brazos, gritó a yoz en cuello:

- ¡Bestias del Diablo! ¡Ténganse quietas y aprendan a portarse como la gente!

¡No fue más! Los animales se detuvieron paralogizados. El "aparecido" avanzaba visiblemente disgustado, por los desmanes fogosos del tronco. Llegó hasta ellos, que asumieron una actitud sumamente bumilde, casi humana; moviendo las orejas, borneando la cola, resoplando amedrentados. El les acarició los morros, reviś́ los arneses, recogió las riendas, se aproximó al pescante y nos vio a todos, aplastando casi a la joven y elegante señora que era nuestra madre. $\mathrm{Al}$ susto reciente nos sobrevino un nuevo asombro, estábamos frente a un extraño. ¡Y, un extraño en los caminos de aquel entonces, significaba más de algol El hombre demostraba el más absoluto respeto.

- iDe buena se ha librado, señora... Hormazábal!

Mi madre, con ese aplomo que la distinguía y ese desplante tan suyo, le respondió: "- $\mid$ En peores cosas me he visto! Pero... ¿quién es usted que me conoce por mi nombre?" 
El hombre sonrió ladino y cazurro, para decir con cierta gracia:

-Cuando las gentes pasan por un bosque, ven árboles, ¡muchos árboles!, coihues, canelos, boldos, alerces, ¡toditos iguales! -era un tono muy especial el del desconocido, tenía un no sé qué de sermón frailuno-, pero, el jel zorro sabe dónde está su madriguera! y distingue "su" árbol del que no lo es... ¿ ¿no es cierto?... ¡Los pobres somos muchos!... los ricos, unos pocos... iy, como son pocos, se les conoce por nombre y apelativo!

Poseía la voz del viejo un raro hechizo; profunda, sonora, llena de inflexiones intencionadas. Nosotros le oíamos embobados y de buena gana le hubiéramos pedido que siguiera hablando. ¡Hasta mi madre se mostraba complacida!

- Si usted quiere... ¿la puedo llevar hasta su casa, señora?

En principio, mi madre, quiso negarse. Pero oscurecía rápidamente, ¡ya, casi, estaba de noche! En otras oportunidades, mi padre, enviaba un criado a nuestro encuentro, pero ya era demasiado tarde y debía suponer que nos habíamos quedado en la ciudad. Para evitar toda resistencia o excusa, el hombre dijo:

- iLlevamos un mismo camino, señora, y además como ando a pie... me serviría para reponerme de la caminata!

- ¡Siendo así, no hago más que agradecerle su atención, suba no más!

El hombre trepó hasta el pescante. A su lado se sentó Juan Miguel; el resto, del todo tranquilizados, volvimos a ocupar nuestros sitios. El menor casi estaba dormido en brazos de mi madre. Pronto, el "aparecido" y el hermano mayor se enredaron en amistosa charla. Las risotadas de ambos despertaron nuestra curiosidad, haciendo que nos arrodilláramos en nuestro asiento, que nos tenía a espaldas de ellos, para acodarnos en el respaldo poniendo nuestras cabezas entre las suyas.

- ¿Usted, cómo se llama? - le preguntó uno de nosotros.

- ¡Se llama Lorenzo! —contestó nuestro hermano- ¡Pero le dicen Loro! 
Se echó a reir y nosotros le secundamos en la mejor forma, con esa propensión de los muchachos de reir con o sin motivo. ¡Además, aquello era gracioso después de todo!... ¡sobre todo después del susto! ¡Y, era tan simpático el viejo!

Llegamos a casa, sin mayor inconveniente, deseosos de contar a nuestro padre cuanto había sucedido. Juan Miguel siguió en el coche hasta las pesebreras, donde el viejo descolgó el carruaje, desenjaezar las bestias para echarlas al campo y guardar los arneses como si hubiera sido el más diligente de nuestros criados. Luego, llevado de la mano, por Juan Miguel, llegó hasta el sitio donde nos encontrábamos ocupadísimos en la enumeración de las incidencias, aumentadas y corregidas y a través de cuya narración mi padre sólo había llegado a imponerse a medias de la gravedad del asunto.

- ¡Ese es el "hombre" de que te hablan los niños! - susurró mi madre, al verle acercarse acompañado de mi hermano.

Mi padre le miró de alto abajo. ¡En buenas cuentas, se miraron! Era característico en mi padre, que como buen montuno que era se había acostumbrado a mirar los árboles desde la copa a la raíz, para apreciar la bondad de su madera o la hermosura del tronco. Aplicaba, igual medida para calar a los hombres, olvidando una sola cosa... ique no eran árboles!

¿Qué vio Lorenzo en mi padre? ¡Sin duda alguna lo que era en sí! Un hombre de cuarenta años, alto, corpulento, rubio, de grandes ojos zarcos.

Nada de eso debe haberle impresionado en demasía al viejo Loro. Para su coleto debe haberse dicho: "Un "rico" como todos o casi todos: blanco, rubio, de ojos azules". ¡Nada de eso debe haberle impresionado! Ni la apariencia autoritaria de nuestra casta. Ya que después en más de una ocasión le oímos decir: “¡Yo estoy curado de espantol" Con lo cual quería demostrar que nada ni nadie podía impresionarle sobre manera.

Por esta vez, el sorprendido, debió ser mi padre, así lo demostró el rictus de sus cejas. Con voz reposada agradeció al hombre su 
gesto, queriendo gratificarle con un billete de cinco pesos. Lorenzo rechazó el obsequio cortés pero indeclinablemente.

- ¿Usted, es forastero? -inquirió mi padre...

La respuesta no se hizo esperar. Las palabras en boca del viejo estaban a flor de labios y revestidas siempre de un raro encanto, eran casi una salmodia.

- ¡Según y cómo, patrón!... ¡me llaman forastero!... ¡nos llaman forasteros! Para mí la tierra es una misma y en todas partes me muevo como el pez en el agua.

- ¿Va de viaje?

- ¡Puede que sí, puede que no...! ¡A lo mejor he llegado al lugar de mi destino, sin darme cuenta siquiera!

Si las respuestas no desagradaron a mi padre - ya que estaban hechas respetuosamente-, se mostró turbado y un tanto amostazado. ¡No estaba acostumbrado a que le respondieran de igual a igual!... tenía fama de soberbio y no hacía más que esforzarse en... mantenerla...

- Si quiere, pase a la cocina a merendar con los peones... y puede alojarse hasta mañana...

- ¡Gracias, patrón!... ¡voy a quedarme!

Se caló el sombrero y dio media vuelta para irse a la cocina, dándonos una mirada de profunda ternura y complacencia. No sé, pero estoy seguro que mis hermanos mayores a igual que yo sentimos una íntima satisfacción al saber que el viejo Loro sería nuestro huésped, aunque no fuera más que por esa noche.

- . . ¡Hijos de tigrel - decía mi padre por nosotros y en verdad la atención con que habíamos presenciado esa entrevista y escuchado el diálogo, no había sido de mera curiosidad. Un secreto instinto nos hizo husmear en aquel encuentro una justa de dos hombres... ¡muy hombres! ¡Dos hombres que se merecían nuestro cariño y admiraciónl

- Jamás pude tutearle! - recordaba mi padre- ¡no sé qué diablos tenía aquel hombre que me inspiraba cariño y respeto!

El viejo Loro era alto, membrudo, de un color tezado que hacía 2-Atenea N.॰ 375 
resaltar la albura de sus cabellos y la pelambre de sus barbas. Sus rasgos eran firmes y nobles, sus gestos, hermosos y distinguidos. Tenía un andar majestuoso, seguro de sí mismo. Sus ojos negros tenían el relumbre de aquellos hechos para escrutar lejanías o vigilar hombres. Tendría setenta años, en cambio, poseía una agilidad moceril e igual frescura había en su espíritu siempre dispuesto a irrumpir en grandes y estruendosas risotadas.

Al día siguiente de su llegada no sé cómo se las ingenió, pero fue él quien ensilló el caballo de mi padre y mucho antes que rayara el sol le aguardaba para pasarle las riendas o servirle en algo oportunamente. ¡No era mi padre hombre fácil de conquistar ni mucho menos!, aunque tampoco iba a pasar por alto el gesto diligente y atento del "afuerino", eso sí que debe haber disimulado en la mejor forma el verdadero efecto que le produjera aquella obsequiosidad. Cabalgó y apenas se había alejado unas metros, cuando se volvió para decirle: usted!

-Espéreme a la hora de almuerzo... ¡tengo que hablar con

Al despertar, mi primer pensamiento fue para el viejo Loro. Estoy seguro de que a mis hermanos les sucedió otro tanto, pues todos nos apresuramos en ir a verle. Su presencia había producido en nosotros la curiosidad infantil y el entusiasmo que despierta un animalito, un nuevo juguete o cualquier monería. ¡Algo nos hacía presentir que Lorenzo se quedaría en casa, que pasaría a ser algo nuestro, para transformarse en una personalidad verdaderamente significativa!

¡Yo no sé cómo se las arregló aquel demonio de viejo! Es del caso que los peones hacendeños, siempre esquivos hacia los forasteros, se le entregaron sumisos desde el primer instante $y$ cuando fuimos a la cocina le encontramos de dueño y señor de todo y de todos.

Al vernos no pudo disimular sentida complacencia proponiéndonos de inmediato ir a poner nasas al río, idea que acogimos con verdadero entusiasmo. ¡El viejo conocía profundamente el alma de los niños! Allá nos dejó hacer cuanto se nos vino en gana, haciéndonos 
colaborar estrechamente en su faena sin pronunciar la consabida frase que tantos desencantos produce en el entusiasmo infantil: "Esto no es para los niños, ¡lo hará cuando sea grandel"

¡Lorenzo no sabía aquella frase!, para él todos éramos pequeños hombres, a quienes había que respetar y de quienes no había que preocuparse más que para evitar algún accidente...

Al regresar, nuestro padre estaba en casa. Encantados le contamos nuestra expedición y labor. Nos escuchó sonriendo, para luego decirnos que había estado observándonos sin que nosotros nos percatáramos de su presencia. Luego se dirigió a nuestro compañero:

-Lorenzo, si usted no tiene trabajo, puede quedarse, jaquí no faltará algo que hacer! Tendrá un pago mensual, ¡claro que si su rumbo es otro... no hay que hablar....

¡Era tan testarudo nuestro padre! Y tan acostumbrado estaba a bravuquear con sus verdaderos y mejores sentimientos. Aquello no era natural en él, lo exigió aquel clima de furia y pujanza en medio del cual vivíamos. ¡El alma de mi viejo era más suave y blanca que vellón de cordero! En el fondo, él más que nadie deseaba que Lorenzo se quedara en casa... sin embargo... ¡cómo sabía sobreponerse!

- ¡Ya estoy quedado, patrón! - respondió el hombre-. A los viejos se nos aquerencian los pies en cualquier pedazo de tierra. Es una forma de ir haciéndonos buena sangre con la idea de la muerte... y la sepultura...

...Así, quedó Lorenzo incorporado a nuestra casa. Los años y el tiempo le granjearon el cariño de mis padres, nuestro amor y el respeto de la servidumbre. Para mi padre, dejarnos al cuidado del viejo Loro, era alivio y certeza de que nada malo podría acontecernos. Durante sus ausencias, por las noches, en torno al brasero y en el cuarto de mi madre, oímos de labios del viejo muchas de las leyendas, consejas e historias saturadas en su madura y humana filosofía, que muchas veces no hago más que repetir para el deleite de quienes aman las historias de esta tierra nuestra. |Así transcurrieron nada menos que veinte años de eterno recuerdo! 
...¿¿Y, el resto? Bueno, el resto es la médula del cuento. Sólo después de veinte años vinimos a parar mientes y a atar cabos sobre multitud de hechos en los cuales, antes, nadie había reparado o que simplemente pasamos por alto cegados por el cariño. Así, para desentrañar la madeja, llegamos a recordar que al segundo día de su llegada, nos dijo: "Esta noche voy a buscar mis cosas". Para marcharse poco después de comer - recién entrada la noche- y no regresar hasta el amanecer del día subsiguiente, caballero en un hermoso overo. Sus arreos eran de primer orden; riendas y lazo de artesanía argentina, frenos, espuelas y enchapaduras trabajadas por los indios, montura de altos pellones y cuero labrado, estribos de nogal de fina talladura y una bestia capaz de tragarse las distancias del mundo. En otro jamelgo conducía una gran lío de chamantos, mantas, alforjas, lanas, cueros, dos o tres mudas de ropa, aparte de pantalones, vestones y chalecos de pana y terciopelo. Al verle, mi padre le dijo con ironía:

- ILo que es hablar por darle gusto a la boca! ¡Digan, ahora, que Lorenzo no tiene más que el cuero pegado al espinazo! ‘Sólo la mujer le hace falta a Lorenzo Aedo!

- Esto es lo que se ve, patrón! -contestó Lorenzo intencionadamente- ¡lo que no se ve está aquíl - golpeándose el pecho en un gesto un poco amargo y cazurro, agregando-: ¿Mujer? ... ¡también la tuve!... pero, ésa, se perdió... para siempre.

Hoy me pregunto si aquel gesto indicando su pecho aludía a sus sentimientos o al dinero que llevaba en su bolsa. ¿Dónde habría ido el viejo en busca de sus bártulos? Fue otra de las preguntas que nos hicimos mucho tiempo después, en cambio mi padre se las había hecho en el momento mismo callando sí sus presentimientos y aprensiones. Por ejemplo, pensó que siendo Lorenzo desconocido de los lugareños, debía proceder de tierras muy distantes. Además estaba en evidencia que había tardado casi cuarenta y ocho horas al ir en busca de sus cosas. Cierto es que se había ido a pie, pero su tranco tragaleguas durante toda una noche de caminata debía conducirle muy al interior. Bien pudo ir a caballo y aquello habría significado 
mayor distancia aún. ¿Cómo se había hecho de aquellos pertrechos? ¿En qué se había desempeñado antes? ¿Sería tal vez un pequeño agricultor que había liquidado sus bienes? Mi padre se inclinó por esta última apreciación, jno valía la pena devanarse los sesos inútilmente!

... Mis hermanos y yo recordamos otros detalles, mejor dicho, un secreto, que guardamos celosamente durante veinte años. Acompañados por el viejo habíamos ido al bosque en busca de copihues. Cuando regresábamos, un hombre nos salió al encuentro. Era un tipo joven, fornido, de aspecto montuno. Al verle, Lorenzo irguió cuanto más pudo su membruda y alta talla, serenamente se encaramó el sombrero sobre la frente - gesto característico cuando algo le parecía mal-, un golpe de cejas trastornó la apacibilidad de su rostro. Puso el ramo de flores que traía en mano de unos de nosotros y decididamente fue al encuentro del hombre, diciéndonos antes:

-Espérenme aquí sin moverse... ¡ese gallo me busca a mí!

El otro le esperaba impasible. A no más de un palmo deben haber estado sus pechos cuando se detuvo Lorenzo. Hablaron en voz baja y sólo las respuestas del viejo llegaron a nuestros oídos, ya que a poco Lorenzo parecía haber perdido el control, cosa extraña en él.

- d........?

- ISí; estoy aquí donde me ves! ¡No es por mi voluntad! ¡La muerte no ha querido llevarme! ¡Bien sabes que nunca le hice el quitel...

$-\{\ldots \ldots \ldots$ ?

- ¿Creen ustedes que los años no pesan? ¿No comprenden que mal que mal la tranquilidad es querencia para todos? ... De aquí no me sacará nadie si no es con los pies para adelantel ... ¡No quiero que se acuerden de mí! ... y yo de nadie me acuerdo!

$-\{\ldots \ldots \ldots$ ?

- ¿Te debo algo?... ¿Me deben algo? ¡Nadie me debe, no debo nada a nadiel |Lárgate, Rosendo, no vaya a ser cosa... que se me caliente la sangre!... Lo único que puedes decirle a los demás 
es que el viejo Lorenzo está muerto en vida! ¡Lárgate, ahora! ¡Lárgate, Rosendo!

No hubo respuesta. El hombre giró sobre sus talones perdiéndose en un quilantar próximo. Nosotros nos habíamos aproximado lentamente. Cuando el otro se hubo marchado, ya estábamos junto a Lorenzo, que temblaba de pie a cabeza. Recobró su ramo y anduvimos un largo trecho silenciosamente, abatido se sentó junto a un árbol respaldándose en el tronco. Estaba fatigado y llevándose el ramo a las narices hundió el rostro en ese puñado de frescura, aspirando profundamente, deseoso sin duda de encontrar un alivio a su viejo y cansado corazón. Para luego condolerse como sólo él sabía hacerlo:

- iLástima grande, que flores tan lindas como éstas no tengan tolor!... iqué hacerle!. . Hay cosas que debieran ser dulces y en cambio son amargas, cosas que debieran ser más claras que el agua y son más oscuras que la sangre... ¡qué diablos!... ¡este mundo es un puro embrollo! —encarándose a nosotros, nos dijo-: ¿Vieron a ese hombre?, pues ¡olvídenlo! ¿oyeron sus palabras? ¡olvídenlas! La vida va a demostrarles en muchas oportunidades lo que voy a decirles en este instante: Hay que aprender a saber callar, aunque veamos lo que veamos, lo importante es ¡saber callar! ¡Eso hace a los verdaderos hombres!... el padre de ustedes es un hombre de verdad... $Y$ yo quisiera que Dios me concediera vida y salud para alcanzar a ver que cada uno de ustedes es un verdadero hombre.

Sobre nuestras cabezas lanudas y rubias, cayeron las manos del viejo en caricia de profunda ternura. Algo así como la unción bíblica de los profetas, que de un simple pastor hacían un rey. ¡No sé cuánta piedad y fe hubo en ese instante en el pecho de Lorenzo, al invocar el nombre de Dios!

Como te dijera anteriormente, nadie como él conocía el alma de los niños. En ese mismo instante habló de mi padre y tocó nuestro amor propio, haciendo que nos consideráramos hombres, únicamente para estar seguro que como tales sabríamos guardar debidamente "aquel secreto". Una vez repuesto, se puso en pie y fue nuevamente alegre y dicharachero a la vez que profundamente humano. 
... No faltó quien recordara otro hecho sugestivo del primer tiempo de la llegada del viejo. Por dos o tres noches seguidas, se sintió un silbido extraño, estridente y prolongado. ¡Era un tiempo aque! en que se vivía sobre las armas!, todo parecía o adquiría caracteres de sospechoso. El oído estaba atento a los más imperceptibles rumores. En cada hombre había despuntado un no sé qué de felino, por cuyo motivo a nadie podía escapar que aquel silbido era una seña, mejor dicho, un "santo y seña". Además, no era lanzado desde un mismo punto, ya venía de un lado, ya del otro. ¡En el mejor de los casos se podía suponer que procedía de un solo individuo! y que los silencios que se seguían era la demora en trasladarse de un sitio a otro. ¿Pero, no era mucho más emocionante suponer que estábamos rodeados por una banda de forajidos? y que aquella estratagema, ¿no era otra cosa que una guerra fría, como se dice actualmente?

¡Te aseguro que fueron noches bien duras, mi querido amigo! Largas e interminables noches de invierno. Esas noches sureñas que tú conoces y que bien pudiéramos llamar: La Madre de la Noche. Pluviosas, retintas, untuosas de agua, plenas de truenos y relámpagos, henchidas de vientos ululantes y poderosos. Noches llenas de resonancias, temores y espanto. El viejo Loro, queriendo deshacer nuestras aprensiones, nos dijo:

-No se les dé nada, yo acallaré a ese pajarraco.

Efectivamente, esa noche, al primer silbido, casi, inmediatamente respondió otro salido desde el centro mismo del patio de nuestra casa. Su estridencia taladró las murallas, se deslizó por los corredores alterando nuestros corazones, jéramos los únicos poseedores del secreto de Loro, sabíamos que él acabaría con aquella amenaza! ¡El que había contestado no podía ser otro que Lorenzo! Al mismo tiempo sentíamos cierta angustia por lo que pudiera acontecer a nuestro buen viejo. Hubo silencio y expectación. Pasó un minuto, o dos, o tres, cuando una detonación conmovió las entrañas de la noche. Sobrevino un largo silencio. ¡ La noche no quiere nada más que lo suyo y sabe sofocar las voces extrañas! 
Al día siguiente, uno de los peones, muy consternado, trajo la noticia que desde el pontón mismo de la casa salía un reguero de sangre seca camino de la montaña. Nosotros le preguntamos algo al respecto a Lorenzo, que nos respondió apesadumbrado:

- Qué diablos!, cuando los hombres no entienden por la buena... |Además, parece que esos demonios se han olvidado de mi modo de hablar!

Ś́lo cuando vinimos a atar estos cabos, recordando hechos y haciendo historia, nuestro padre también nos puso al tanto de algo que hasta entonces había mantenido en secreto. Había sucedido años después de la llegada del viejo. Iban a empezar las faenas de nuestro tercer aserradero. Mi padre llevaba ese día víveres y dinero. La tropilla le llevaba una ventaja de una o más horas de camino. Mi padre y Lorenzo galopaban en el deseo de llegar al aserradero antes del anochecer, cuando vieron que a su encuentro venía un grupo de jinetes, que al verles abandonaron el camino tomando las huellas de herraduras, empezando a marchar en fila india en el visible deseo de encajonarles, ya que por donde ellos habían tomado se alzaba dos o tres metros sobre el camino mismo.

- ¿Qué te parece, Lorenzo? -musitó mi padre.

- iLa cosa es seria, patrón! Atrabuque usted por su cuenta, patrón, pero no dispare antes que yo lo haga, ¡si es que me dejan hacerlol

Sin decir más, clavó espuelas al caballo yéndose en derechura al que encabezaba el grupo. Cambiaron algunas palabras. Luego mi padre oyó la voz de Lorenzo que le gritaba:

- A Ande no más, patrón, son amigos...!

Así como mi padre avanzaba, vio que los otros seguían su rumbo y que al pasar junto a él musitaban algo, que bien podía considerarse como un saludo. No pudo ver bien sus rostros, porque llevaban el sombre caído sobre los ojos. Lorenzo se había desmontado y atravesando la cabalgadura en el camino estaba atrincherado tras ella.

Al reunirse nuevamente, Lorenzo le sonrió: 
- Qué tal, patrón!.. ¡como susto estuvo bueno, pero si no viene con este viejo, aquí mismo entrega su alma a Dios!

- ¡Para qué te bajaste del caballo! —en verdad, mi padre, se empeñaba en desviar la conversación, tratando de restarle importancia al hecho, aunque presentía que nada bueno pudo haber salido de aquel maldito encuentro.

- ¿Las preguntas suyas!... para atrincherarme, pues, para qué iba a ser ¿entonces?... Aquí estaba por si llegaban a faltar a su palabra o, mejor dicho, por si querían faltarme al respeto... ¡desde aquí los tenía asegurados!... jle aseguro que ni uno solo escapa con vida!

- ¿Qué tienes bajo la manta?

—¿Qué va a ser, pues, patrón...? jesto no más!

Le mostró una carabina recortada.

-Cuando te vi correr hacia ellos, me dije: "Lorenzo se pasó al otro lado" —chanceó mi padre, pero, en verdad, tuvo ese presentimiento.

- ¿Lo dice, en verdad, patrón?

Confesaba mi padre no haber visto nunca hasta entonces un gesto de mayor dignidad ofendida, al mismo tiempo que de más fiereza, preguntándole:

- ¿Por acaso tengo cara de traidor?

- Es una broma, hombre!

- Como broma, la aceptol

Tras un breve silencio, el suficiente como para que se serenara su ánimo, Lorenzo volvió a hablar:

-Las manos y la cara del hombre son el retrato de su alma... ni mis manos ni mi cara tiene sello de traición!... |Traidor! |Traidor $-\mathrm{y}$ con gesto de profundo orgullo escupió con rabia, deseoso de limpiar sus labios de tan inmunda palabra.

...Ese mismo día conversaron muchas otras cosas. Ya Lorenzo había recobrado su buen humor y le decía:

- iTarde nos vinimos a conocer, patrón! Yo ya soy un viejo y 
usted tiene su hogar formado... ¿De no ser las cosas así, cree usted que alguien nos habría puesto atajo en algo?

...Hoy día yo comparto en todo la opinión del viejo. No es que mi padre fuera deshonesto o arbitrario, pero era hombre ¡muy temerario! Con Lorenzo, y de no mediar las dificultades por él mismo mencionadas, no dudo que hubieran llegado a ser los dueños de la montaña. Ahora... y esto sea para los dos únicamente, aunque mi padre no lo confesara, por delicadeza o temor de que fuéramos a encontrar indigno algún acto suyo y sin que mis pensamientos ofendan su memoria, creo que en compañía de Lorenzo realizó más de algún negocio oscuro. ¡Mucho me dà que pensar que la mayor prosperidad de mi padre se inició con la llegada del viejo! ¡Con el cariño que nos tenían ambos!, qué no hubieran hecho por asegurarnos un porvenir brillante...

No recuerdo si en aquella oportunidad, la última que estuve con mis viejos, se hizo memoria de otros detalles, aunque para el objeto de mi cuento no es necesario un mayor número de anécdotas.

.. Como comprenderás, veinte años habían sido tiempo suficiente para transformarnos en hombres hechos y derechos, Juan Miguel tenían treinta y dos años y José Luis, que le seguía en edad, ambos habían recibido su título de abogado y ejercían en el norte. Wáshington y yo, egresados de medicina, habíamos fijado nuestra residencia aquí en la capita!, Federico y Romeo, arquitectos ambos, habían ido al extranjero en cuanto recibieron su diploma, el menor acababa de dar bachillerato y veraneaba en Magallanes. Los viejos estaban solos, acompañados de Lorenzo, que ya no era un extraño, sino un verdadero y querido pariente. Así estaban las cosas, cuando sobrevino el desenlace. ¡Escucha!

Mi padre gozaba de gran consideración en toda la zona, ya no vivía en la hacienda, sino en Temuco. Aquel día almorzaba en casa un Ministro de la Corte de Valdivia y algunos otros invitados. Por extraño designio Lorenzo aceptó sentarse a la mesa, cosa que no hacía a diario.

¡Sus noventa años le hacían mella!, por cuyo motivo fue el últi- 
mo en llegar. Ya todos estaban instalados y su sitio estaba frente al ex Ministro. Hubo una breve presentación con las consabidas palabras de mi padre:

- ¡Señor Ministro, un viejo servidor... mi brazo derecho!

Ante la sorpresa de mi padre, ambos ancianos se irguieron y se miraron primero con simple estupor, luego con furia y encono, para disimular la desagradable sorpresa. El primero en hablar fue Lorenzo que sonrió irónico:

- ¡Vaya si nos conocemos!

- ¡Nos conocemos hace cincuenta años, o más! ¡mucho más!... jotro montón de tiempo nos habíamos perdido de vista!...

- ¿Dónde? ¿Cuándo? -preguntó mi padre.

El ex Ministro desvió la conversación. Ni una sola vez se desplegaron los labios del viejo servidor, pero mi padre advirtió su aire de cansancio y malestar. Contrariamente a su costumbre, mantenía la cabeza baja y no se veía en su rostro ese gesto de tensión muscular que denotaba su tremenda energía, sino, al contrario, toda su piel parecía haberse aflojado en una mueca de angustia. Al término del almuerzo pidió permiso para retirarse.

Al momento de partir, el ex Ministro preguntó a mi padre:

-Perdone usted, señor Quiñones, ¿cuántos años ha que este hombre está a su servicio?

- Hace más de veinte años, señor Ministro!

Contándole cuanto acabo de narrarte, agregándole hechos y detalles que no hacían más que ponderar la acrisolada honradez de Lorenzo, su espíritu de trabajo y la diligencia que demostraba a pesar de sus años, resaltando su hombría de bien y corrección. El buen señor escuchaba en silencio, golpeando con los guantes la palma de su mano, por fin exclamó:

—Parece increíble!

- ¿Se conocían?

— Sí!, pero guárdeme el secreto. Le conozco desde que me inicié como abogado hace sesenta y cinco años. Usted sabe tan bien como yo que entonces la vida aquí era casi una verdadera guerra. Fue mi 
cliente en muchas oportunidades. En aquel tiempo yo era un muchacho. $¡ \mathrm{El}$ también lo era! Yo quería hacer fortuna a toda costa y mis clientes... no fueron siempre las mejores personas, defendí durante mucho tiempo a los facinerosos, jeran los que pagaban mejor!... ¡Este hombre estaba entre ellos!

“ ¡Después las cosas cambiaron! Vino mi iniciación en la carrera judicial y mis clientes de ayer pasaron a ser mis enemigos, ¡muchas veces mi vida corrió peligros! Fue así como de la noche a la mañana me convertí en el más encarnizado enemigo y perseguidor de los delincuentes, conocía todas sus tretas y escondites, sus mañas y artimañas, ¡a eso más que a nada debo el brillo de mi actuación!... IA veces me da vergüenza tan sólo pensarlo!

"¡Qué tiempos eran aquellos, Dios mío! Le digo estas cosas, señor Quiñones, porque algún día debía comunicárselas a alguien. |Alguien que como yo hubiera vivido también aquellos tiempos de demasías! ¿No es así?

Mi padre hubiera querido negar. ¡No se atrevió a hacerlo! ¡Era un hombre demasiado honrado!

- ¿Cómo me dijo que se llamaba ese hombre?

- ILorenzo Aedo Ormeñol

- iNo, ese no es su verdadero nombre... ino lo recuerdo siquiera!... Esta será la última vez que le vea. ¡No pocas veces nos hemos enfrentado!... primero como amigos, luego como enemigos, ¿hoy día? no puedo acertar! Pues, bien, en su casa, amigo Quiñones, ha tenido usted a un verdadero león. ¡Este fue el más terrible de los bandoleros! ¿Cómo no serlo? Era el más inteligente, el más valeroso y astuto... Otros, menos criminales que él, se han podrido en presidio... Su casa ha estado custodiada por el demonio en persona, pero "dad al César". .. jeste roto es muy hombre! jes un gran roto! ... No bien se hubo ido el Ministro, mi padre fue al cuarto de Lorenzo. ¡No estaba! El ama de llaves informó que había hecho enganchar el coche y había salido. Hubo que esperar el regreso del cochero, quien dijo que don Loro lo había hecho volverse desde la plaza de la Estación. Sólo por la noche mi padre tuvo la certeza 
que Lorenzo se había embarcado. Nosotros, los que residíamos en Santiago, recibimos orden de ir a la llegada de todos los trenes sin que jamás tuviéramos el menor éxito.

Poco a poco y uno tras otro llegamos a tener minucioso detalle del desaparecimiento de Lorenzo. Las suposiciones fueron casi todas idénticas. El viejo había desembarcado en alguna estación cercana. Habría dambiado sus ropas y como un simple campesino debió perderse en quizá qué villorrio. ¿Por qué lo hizo? ¿Quién le habría dicho nada? ¿A quién entre nosotros iba a importar la crítica de su pasado? ¿No se había reivindicado en veinte años de reiterada nobleza? ¡Pero es que la hombría, la dignidad de Lorenzo, no podía resistir la más leve sospecha! No tuvo el valor suficiente para afrontar la presencia de esos niños que él deseó hombres sobre todas las cosas.

...Lorenzo era un convencido de las eternas sorpresas de la vida y estaba preparado para las mayores eventualidades. Junto a nosotros había amasado una respetable fortuna que llevaba consigo y que jamás aceptó depositar. ¡Le habrá servido hasta el fin de sus días! ¡Pensar que como mis viejos, bien pudo él morir rodeado de nuestro cariño! En cambio optó por la costumbre de las fieras, buscó la soledad.

- ¿Nunca supieron de él?

-... nunca!

- ¿Hasta qué punto tu relato es creíble, amigo mío?

- iIntegramentel ¡Ah, pero olvidaba un detalle!... ¡No, mejor nol es demasiado tarde... ¡Será para otra oportunidad! 